\title{
Dinamika Sosial Terhadap Peran Lembaga dalam Masyarakat di Bidang Peternakan di Desa Lompo Tengah Kecamatan Tanete Riaja Kabupaten Barru
}

\author{
The Dynamics of Social on the Role of Institutions in Animal Livestock Community \\ at the Village of Lompo Tengah, Tanete Riaja Subdistrict, Barru Regency
}

\section{Mursidin}

Jurusan Ilmu Peternakan Fakultas Sains dan Teknologi

Universitas Islam Negeri Alauddin Makassar

Email : mursidin.natsir@uin-alauddin.ac.id

\begin{abstract}
ABSTRAK
Penelitian ini bertujuan untuk mengetahui sejauh mana masyarakat mampu menghadapi berbagai masalah yang dialami khususnya menyangkut dinamika sosial terhadap peran lembaga dalam masyarakat dalam bidang peternakan di Desa Lompo Tengah Kecamatan Tanete Riaja Kabupaten Barru.Metode yang digunakan dalam penelitian ini adalah kualitatif dengan proses FGD (Focus Group Discussion) secara mendalam dengan ketua kelompok tani/ternak dan anggotanya serta tokoh masyarakat dengan membahas tentang masalah dan kelemahan yang ada dalam dinamika sosial terhadap peran lembaga masyarakat dalam bidang peternakan di Desa Lompo Tengah Kecamatan Tanete Riaja Kabupaten Barru.Hasil penelitian yang di dapatkan tentang Dinamika sosial di Desa Lompo Tengah, Kec. Tanete Riaja, Kab. Barru begitu mencolok. Dimana banyaknya ketimpangan yang terjadi antara kelompok tani ternak dalam pembagian bantuan sapi potong oleh pemerintah kemudian akibatnya berdampak pada kecemburuan sosial masing-masing induvidu disebabkan karena pembagian tersebut tidak merata, akibatnya terjadi konflik yang dapat menimbulkan pertikaian karena akibat dari konflik tersebut maka menimbulkan perubahan sikap di masyarakat yang mempengaruhi aktivitas kerja. Kelompok tani/ternak yang ada di Desa Lompo Tengah kini sudah tidak seaktif dulu dan program penyuluhan pun menjadi kurang aktif dalam meningkatkan produktivitas dalam bidang peternakan di desa tersebut.
\end{abstract}

Kata kunci: Dinamika Sosial, Kabupaten Barru, Lembaga Masyarakat

\begin{abstract}
This study attempts to understand the extent of the people were able face the issues experienced particularly in relation to social dynamics on the role of agency in the community in breeding in the central Lompo Tengah in tanete riaja subdistrict, Barru district. Methods used in research is in the process of the FGD qualitative (focus group discussion) deeply and chairman / livestock farmers groups and their members and community leaders to speak of problems and weakness in the dynamics of social on the role of elements in breeding in the central Lompo Tengah,Tanete Riaja subdistrict, Barru district.The results of research in get about of dynamics of the social in the village lompo the middle


of.Tanete Riaja, Barru district.Barely making so striking. Where is the large number of lameness going on between the farmers group of the cattle on the division of aids in the form of beef cut into by the government then established as a result has had an impact on the result of social jealousy induvidu it is because of ways the distribution will be uneven, as a consequence there was conflicts that have can give rise to the feuding have collapsed of a conflict because due to the capital market and financial give rise to a change in attitude in the community.The farmers group of the / the livestock they are were running in their village Lompo Tengah losers at racing genk on her amid the dire straits are those that are not before and the socialization program then becomes a less active in making commodities which are considered profitable a farm in the villages that there is indeed.

Keywords: Barru Regency, Community Institution, Social Dinamycs

\section{PENDAHULUAN}

Komoditas ternak di indonesia mengalami sejumlah penurunan. Selain pola pemeliharaan, kondisi alam membuat suplai pakan dan air pada musim kemarau menurun. Partisipasi masyarakat serta keikut sertaannya dalam meningkatkan komoditas peternakan saat ini sangat diperlukan. Beberapa hal yang menjadi hambatan dalam pengembangan peternakan indonesia yaitu terbatasnya modal peternak, wabah penyakit ternak yang menyerang serta kurangnya perhatian masyarakat terhadap kelangsungan produktivitas ternak.Masyarakat merupakan sekelompok orang yang membentuk sebuah sistem semi tertutup, di mana sebagian besar interaksi adalah antara individu - individu yang berada dalam kelompok tersebut. Peran masyarakat dalam dinamika sosial sebagai sumber informasi dalam munculnya dinamika sosial. Masyarakat juga salah satu faktor penting dalam berdinamika sosial dikarenakan mereka merupakan sebagai pelaku utama dalam sosial (Soebandono, 2015).

Dinamika sosial merupakan kumpulan kelompok - kelompok yang membentuk organisasi sosial dan bersifat kompleks. Didalam organisasi tersebut ada norma- norma, nilai - nilai dan pranata sosial. Disamping itu dalam organisasi sosial terdapat peraturan peraturan untuk bertingkah laku yang kesemuanya berinteraksi dalam kehidupan bermasyarakat. Studi tentang dinamika sosial pada umumnya menggunakan model atau rumus metodologis untuk menjelaskan tren sosial yang muncul. Model metodologis yang digunakan adalah rumus untuk menganalisis data empiris baik yang berbentuk narasi (kualitatif) atau numerik (kuantitatif). Penggunaaan model menyiratkan aspek kumulatif dalam analisis dinamika sosial. Secara sosiologis, dinamika sosial berarti perubahan sosial 
yang terjadi secara reguler yang diukur dengan menggunakan model atau rumus. (Santika, 2016).

Beberapa topik yang menjadi fokus dalam studi tentang dinamika sosial yaitu dinamika kelompok, dinamika keluarga, dan dinamika penduduk. Sebagai contoh, studi tentang dinamika penduduk akan fokus pada aspek pertumbuhan atau penurunan jumlah penduduk yang pengukurannya dilakukan secara reguler. Dengan pengukuran reguler, terlihat tren kenaikan atau penurunan penduduk di suatu daerah atau negara. Proses perubahan tren tersebut disebut sebagai dinamika sosial (Murtujo, 2014).

Berdasarkan Survei awal yang telah dilakukan di Desa Lompo Tengah Kecamatan Tanete Riaja Kabupaten Barru, kondisi dinamika sosial terhadap peran lembaga dibidang peternakan masih banyak terjadi ketimpangan antara kelompok tani/ternak yang berdampak pada kurangnya peran lembaga masyarakat yang berpartisipasi dalam kerjasama bagi hasil untuk meningkatkan populasi ternak khusunya komoditi ternak sapi bali murni. Masalah ini kerap terjadi dalam lembaga masyarakat yang dapat berakibat fatal terhadap usaha peternakan yang mereka geluti. Hal inilah yang mendasari peneliti ingin melihat sejauh mana dinamika sosial yang ada di Desa Lompo Tengah Kecamatan Tanete Riaja Kabupaten Barru. Melihat kondisi yang terjadi terhadap dinamika sosial yang berperan dalam lembaga masyarakat maka hal inilah yang melatarbelakangi dilakukannya penelitian tentang "Dinamika Sosial Terhadap Peran Lembaga Dalam Masyarakat diBidang Peternakan".

Tujuan dari penelitian tentang dinamika sosial terhadap peran lembaga masyarakat dalam bidang peternakan yaitu untuk mengetahui sejauh mana masyarakat mampu menghadapi berbagai masalah yang dialami khususnya menyangkut dinamika sosial terhadap peran lembaga dalam masyarakat dibidang peternakan.

\section{METODE}

Penelitian mengenai Dinamika Sosial terhadap peran lembaga masyarakat dalam masyarakat dilaksanakan pada bulan Februari sampai dengan bulan Mei 2018 yang bertempat di Desa Lompo Tengah Kecamatan Tanete Riaja Kabupaten Barru. Jenis data yang digunakan dalam penelitian ini adalah kualitatif merupakan data yang berupa fakta-fakta atau kejadian dilokasi penelitian yang berupa kalimat atau pertanyaan yang sesuai dengan kebutuhan dalam penelitian ini yaitu data primer dan sekunder. 


\section{Metode Pengumpulan Data}

Metode pnegambilan data yang dilakukan pada penelitian mengenai dinamika sosial terhadap peran lembaga dalam masyarakat di Desa Lompo Tengah, Kec. Tanete Riaja, Kab. Barru adalah dengan melakukan penyuluhan kepada para kelompok tani/ternak serta petuah adat setempat serta melakukan proses FGD (Focus Group Discusion) dimana FGD ini dilakukan dengan proses wawancara secara langsung terhadap masyarakat khusunya kelompok tani/ternak. Yang dimaksud wawancara dalam penelitian ini yaitu proses memperoleh keterangan atau informasi penanya atau peneliti dengan petani/peternak (informan) dengan menggunakan alat yang digunakan Interview Guide (panduan wawancara).

\section{Kegiatan Penelitian}

Kegiatan yang dilakukan pada penelitian mengenai Dinamika Sosial Terhadap Peran Lembaga Dalam Masyarakat di Desa Lompo Tengah Kec. Tanete Raja, Kab. Barru adalah FGD (Focus Group Discusion). FGD merupakan suatu diskusi tanya jawab yang dilakukan secara sistematis dan terarah mengenai suatu masalah tertentu. FGD berfungsi sebagai salah satu metode pengumpulan data dimana peneliti melakukan diskusi secara mendalam yang melibatkan semua lapisan masyarakat khususnya ketua kelompok tani/ternak serta para anggotanya, penyuluh peternakan yang bertugas di wilayah tersebut dan para tokoh - tokoh adat.

\section{HASIL DAN PEMBAHASAN}

\section{Kajian Focus Group Discusion (FGD) dan Penyuluhan di Desa Lompo Tengah}

Berdasarkan hasil FGD tentang dinamika sosial terhadap peran lembaga dalam masyarakat dibidang peternakan di Desa Lompo Tengah di dapatkan berbagai macam pendapat mulai dari system pemeliharaan khususnya sapi potong di daerah ini yang awalnya pola pemeliharaan yang dilakukan masih secara liar karna tidak memilki kandang dan pemberian vaksin tidak merata disebabkan pemberian bantuan tidak sampai ke desa tersebut. Ada 7 kecamatan di Kabupaten Barru, adapun Kecamatan Tanete Riaja terpadat populasi sapinya \pm 12.000 ekor. Dahulu pemeliharaan ternak sapi di Kecamatan Tanete Riaja dilakukan dengan dilepas secara bebas namun seiring berjalannya waktu sudah mulai dikandangkan. 
Desa Lompo Tengah saat ini bekerja sama dengan Bank Indonesia dalam hal pemberian fasilitas kandang dan juga bekerja sama dengan UNHAS (Universitas Hasanuddin) dimana pihak UNHAS memberikan modal kemudian masyarakat yang mengelola dana tersebut. Di Desa Lompo Tengah ada 24 Kelompok Tani/Ternak dimana kelompok tani ini setiap kali ada ternak yang lahir harus ditimbang, diukur, dimana fasilitasnya disediakan pusat, dan di Desa Lompo Tengah ini tidak boleh ada sistem kawin pada ternak yang notabenenya sedarah (Inbreeding). Hal ini sesuai dengan pendapat Hughers (2006) bahwa kerja sama sebuah lembaga dan masyarakat khususnya petani/peternak memberi pedoman bagi anggota masyarakat dimana mereka harus berupaya menghadapi masalah-masalah yang terjadi terutama yang menyangkut kebutuhan dalam peningkatan usaha.

Memenuhi kebutuhan dalam program pengembangan sapi bali murni di Desa Lompo Tengah berbagai macam program telah lakukan, mulai dari program Pembibitan Sapi Bali Asli yang bebas dari 10 penyakit, dan desa ini juga memilki program Upaya Khusus Sapi Induk Wajib Bunting. Selain itu memiliki program showroom sapi yang bertujuan untuk mengetahui ternak yang keluar masuk di daerah ini serta dapat memantau harga jual beli ternak sapi. Selanjutnya program P3T Mandiri (Pos Pelayanan Peternakan Terpadu), fungsi dari pos pelayanan ini yaitu setiap dusun yang ada di Desa Lompo Tengah memiliki petugas peternakan yang bertugas memberikan penyuluhan kepada masyarakat dan memberi solusi penyelesaian jika ada ternak yang terkena penyakit. Hal ini sesuai dengan pendapat Mardikanto dkk (1993) bahwa program yang telah di susun oleh pemerintah dalam pengembangan produktivitas mengharuskan keikutsertaan dan partisipasi masyarakat serta para instansi (penyuluh) dalam mencapai sasaran pada program - program yang telah dirancang.

Adapun hal lain yang terkait dalam pola pemeliharaan ternak sapi bali yang ada di Desa Lompo Tengah yaitu adanya perubahan aturan sistem lepas yang mengharuskan ternak dikandangkan karena adanya peraturan daerah yang kemudian diturunkan menjadi peraturan desa, di mana peraturan desa tersebut berbunyi jika ada ternak yang dilepas dan merusak tanaman masyarakat maka pemilik ternak tersebut harus bertanggung jawab dengan membayar denda/ganti rugi tergantung apa yang dirusak oleh ternaknya. 


\section{Dinamika Sosial terhadap Peran Lembaga Dalam Masyarakat Dibidang Peternakan}

Berdasarkan hasil wawancara dengan para kelompok tani/ternak, dinamika sosial di Desa Lompo Tengah Kec. Tanete Riaja Kab. Barru begitu mencolok. Dimana banyaknya ketimpangan yang terjadi antara kelompok tani ternak dalam pembagian bantuan sapi potong oleh pemerintah, kemudian akibatnya berdampak pada kecemburuan sosial masingmasing induvidu disebabkan karena pembagian tersebut tidak merata, akibatnya terjadi konflik yang dapat menimbulkan pertikaian karena akibat dari konflik tersebut maka menimbulkan perubahan sikap di masyarakat. Hal ini sesuai dengan pendapat Hanifa (2012) yang menyatakan tentang teori Dinamika di antaranya teori evolusi menejelaskan adanya perubahan sosial membuat masyarakat menjadi lebih individual dan sikap kemasyarakatan semakin berkurang.

Adapun pendapat yang dikemukakan oleh petua adat setempat menyatakan bahwa banyak keluhan yang dialami oleh para peternak yang paling krusial dan sering di alami oleh peternak adalah kendala pertumbuhan berat badan pada ternaknya. Dapat dikatakan bahwa dinamika dalam pemeliharaan ternak sapi bali masih terjadi, dan beliau juga menyebutkan bahwa biasanya penurunan berat badan di pengaruhi oleh perubahan cuaca dan kualitas pakan. Hal ini sesuai dengan pendapat Santika (2016), yang menyatakan bahwa faktor Dinamika sosial yang terjadi dapat di pengaruhi bukan hanya dari manusianya namun lingkungan alam yang ada di sekitar manusia menjadi salah satu faktor penyebabnya.

Informan selanjutnya memiliki pendapat yang berbeda dengan yang lainnya pertama karna merupakan warga asli Desa Lompo Tengah yang memiliki lahan pertanian sendiri untuk digarap, dan termasuk salah satu anggota kelompok tani yang sering mendapat bantuan berupa alat-alat pertanian dari pemerintah berupa traktor sehingga dapat mengolah lahan pertanian dengan mudah dan lebih efisien, hal ini sesuai dengan pendapat Santika (2016) yang menyatakan salah satu faktor terjadinya perubahan sosial yaitu adanya penemuan baru dari cara hidup yang telah di terima yaitu berupa kemajuan teknologi untuk memudahkan mengelolah usaha di bidang masing-masing.

\section{Peran Lembaga Dalam Masyarakat Dari Aspek Sosial Dibidang Peternakan}

Berdasarkan hasil wawancara yang dilakukan mengenaiperan lembaga masyarakat dari aspek sosial di Desa Lompo Tengah bahwa peran lembaga cukup baik dalam 
membantu masyarakat,bantuan kerjasama tersebut berupa obat-obatan serta berbagai system atau cara pemeliharaan secara intensif dan sebagai sarana untuk mendapatkan informasi lainnya mengenai system pemeliharaan ternak sapi bali. Semua ini bertujuan untuk meningkatkan produksi ternak sapi balikhususnya di Desa Lompo Tengah, Kec. Tanete Riaja Kab. Barru, Namun adapun yang dikatakan oleh anggota kelompok tani/ternak bahwa tidak bisa di pungkiri, dari semua bantuan yang dilakukan oleh lembaga masih tidak merata, ada yang mendapatkan dan ada yang tidak mendapatkan sama sekali, akhirnya berbagai pendapat yang di kemukakan oleh para kelompok tani/ternak ini bervariasi. Hal ini sesuai dengan pendapat Kusuma (2012), yang menyatakan adanya bantuan pada berbagai kehidupan sosial dan budaya masyarakat akan memberi pengaruh yang luas bagi kehidupan masyarakat, pengaruh itu berdampak pada perilaku terciptanya perilaku sosial yang baru sekaligus menggeser norma-norma sosial yang lama.

Kondisi peran lembaga masyarakat yang ada di Desa Lompo Tengah masih kurang efektif dan belum tepat sasaran serta kurang terorganisir, karena lembaga tersebut hanya mau membantu untuk orang-orang atau peternak yang memiliki keahlian yang baikdan keakraban dengan pihak lembaga, jika bergabung dalam kelompok tani ternak namun belum memiliki kemampuan yang sesuai dengan yang diinginkan maka tidak dapat di berikan kepercayaan oleh lembaga yang bersangkutan, Sehingga masyarakat yang ingin berkembang dalam bidang peternakan terkendala dalam hal tersebut, kondisi seperti ini biasanya di latarbelakangi oleh faktor politik dalam suatu daerah. Hal ini sesuai dengan pendapat Murtujo (2014), yang menyatakan bahawa konflik berasal adari pertentangan kelas antara kelompok tertindas dan kelompok penguasa sehingga akan mengarah pada perubahan sosial. Artinya masyarakat yang tidak terlalu diperhatikan oleh lembaga masyarakat di masukkan dalam kelompok yang tertindas, sedangkan lembaga masyarakat yang merupakan lembaga yang di pengaruhi oleh politik merupakan kelompok penguasa.

Peran kepala desa di Desa Lompo Tengah sangat aktif, kepala desa memiliki keinginan membantu masyarakat yang belum mendapat bantuan dengan cara memberikan ide dan gagasan kepada masyarakat dengan membuat program yang dapat mensejahterahkan anggota kelompok tani/ternak. Contohnya memberikan kelompok tani /ternak 2 ekor sapi jantan dan betina bagi anggota yang belum mendapatkan, apabila ternak tersebut melahirkan pedet maka akan di bagi ke masing-masing anggota kelompok tani/ternak yang lain,sehingga masyarakat dapat meningkatkan keahliannya dalam bidang peternakan 
khususnya pemeliharaan ternak sapi bali. Hal ini sesuai dengan pendapat Richard (2012) yang menyatakan bahwa teori fungsional adalah sebuah teori menekankan perubahan pada fungsi-fungsi lembaga sosial dalam masyarakat. Masyarakat memilih sistem sosial yang saling berhubungan satu sama lain. Sistem tersebut bergerak untuk mewujudkn tujuan dan memenuhi kebutuhan hidup masyarakat.

\section{KESIMPULAN}

Dinamika sosial di Desa Lompo Tengah Kec. Tanete Riaja Kab. Barru begitu mencolok. Dimana banyaknya ketimpangan yang terjadi antara kelompok tani ternak dalam pembagian bantuan sapi potong oleh pemerintah, kemudian akibatnya berdampak pada kecemburuan sosial masing-masing induvidu disebabkan karena pembagian tersebut tidak merata, akibatnya terjadi konflik yang dapat menimbulkan pertikaian karena akibat dari konflik tersebut maka menimbulkan perubahan sikap di masyarakat.

Peran lembaga dalam masyarakat cukup baik dalam membantu masyarakat, bantuan kerjasama tersebut berupa obat-obatan serta berbagai system atau cara pemeliharaan secara intensif dan sebagai sarana untuk mendapatkan informasi lainnya mengenai system pemeliharaan ternak sapi bali. Semua ini bertujuan untuk meningkatkan produksi ternak sapi bali khususnya di Desa Lompo Tengah, Kec. Tanete Riaja Kab. Barru, Namun adapun yang dikatakan oleh anggota kelompok tani/ternak bahwa tidak bisa di pungkiri, dari semua bantuan yang dilakukan oleh lembaga masih tidak merata ada yang mendapatkan dan ada yang tidak mendapatkan sama sekali, akhirnya berbagai pendapat yang di kemukakan oleh para kelompok tani/ternak ini bervariasi.

Disarankan kepada masyarakat khusunya para kelompok tani/ternak di Desa Lompo tengah sebaiknya mencari solusi dari yang dialami serta peran lembaga dalam masyarakat dibidang peternakan lebih diaktifkan khususnya, agar kehidupan masyarakat dalam berlembaga lebih produktif dan mampu meningkatkan taraf hidup.

\section{DAFTAR PUSTAKA}

Hanifa. 2012. Lembaga Kemasyarakatan (Sosiologi).http: // anisanajwa. blogspot. com/2016/01/ lembaga - masyarakat - sosiologi. html. Diakses Oktober 2016.

Hughers. 2006. Sosiologi. Jakarta: Rajawali Press.

Kusuma. 2012. Kelembagaan Masyarakat.http://kusuma. blogspot.com. Diakses Oktober 2016.

Mardikanto. 1993. Petunjuk Penyuluhan Pertanian. Usaha Nasional, Surabaya. 
Murtujo. 2014. Pengertian Dinamika. ITS, Bandung.

Richard T. Schaee. 2012. Metode Praktikum Masyarakat. GramediaPustaka Utama, Jakarta. Santika. 2016. Dinamika Masyarakat. UNM Famika, Makassar Soebondono. 2015. Bagian - Bagian Faktor Dinamika. Universitas Bengkulu, Benggkul. 